\title{
A COMPARATIVE EVALUATION OF THE EFFICACY OF TRIPLE DRUG THERAPY WITH DUAL DRUG THERAPY IN COPD PATIENTS
}

\author{
PATHAN AMANULLA KHAN ${ }^{*}$, A. SUJALA ${ }^{2}$, B. B. SARAH NOUSHEEN ${ }^{3}$, AYESHA FARHATH FATIMA ${ }^{4}$, HIBBA TUL \\ ALA $^{2}$, A. B. T. PALLAVI REDDY ${ }^{2}$
}

1Department of Clinical Pharmacy and Therapeutics, Anwarul Uloom College of Pharmacy, Hyderabad, Telangana, India, ${ }^{2}$ Department of Pharmacy Practice, Bharat Institute of Technology-Pharmacy, Hyderabad, Telangana, India, ${ }^{3}$ Pharm D $4^{\text {th }}$ year, Anwarul Uloom College of Pharmacy, Hyderabad, Telangana, India, ${ }^{4}$ Department of Pharmaceutics, Anwarul Uloom College of Pharmacy, Hyderabad, Telangana, India Email: aman.pathan811@gmail.com

Received: 30 Dec 2017 Revised and Accepted: 08 Mar 2018

\section{ABSTRACT}

Objective: The present study was conducted with the objective of analyzing the efficacy of triple-drug combination therapy (formoterol, ciclesonide, tiotropium) by comparing it with double drug combination therapy (formoterol, budesonide).

Methods: A prospective observational study was conducted. Sixty patients were enrolled, and divided into two groups of thirty each; one group was treated with the double-drug and the other with a triple drug combination. FEV1 and FVC pre-and post-treatment in either group were assessed spirometrically. Score ranges of 0-10,11-20 and 21-30 were allotted to mild, moderate and severe categories and results were analyzed statistically.

Results: Of the 60 patients recruited, $61-70$ y olds constituted the majority (35\%) of the population. Males (63.3\%) were more in number compared to females (36.6\%). Twenty-three of thirty-eight men smoked (60.5\%); there were no female smokers. Common symptoms included cough (93.3\%), dyspnoea (85\%), fever (45\%) and haemoptysis (15\%). Hypertension accounted for 70\% of patient comorbidities, followed by diabetes (60\%) and cardiovascular diseases (40\%). Three months after treatment with triple therapy, a significant increase in the differences of means of both FEV1 (14.27) and FVC (14.90) values was observed. Further analysis based on score ranges demonstrated that triple therapy administration markedly reduced the number of patients suffering from severe COPD.

Conclusion: Our comparative analysis indicated that triple therapy was more effective in improving lung function, enhancing patients' quality of life (evidenced from score ranges) thereby reducing mortality. While much is known about the greater effectiveness of triple over dual therapy, researchers to formulate the most effective triple therapy are in progress.

Keywords: Chronic obstructive pulmonary disease (COPD), Inhaled corticosteroids, Long-acting $\beta 2$ agonist, Long-acting muscuranic antagonist, Spirometry (C) 2018 The Authors. Published by Innovare Academic Sciences Pvt Ltd. This is an open access article under the CC BY license (http://creativecommons.org/licenses/by/4.0/) DOI: http://dx.doi.org/10.22159/ijpps.2018v10i4.24529

\section{INTRODUCTION}

The history of COPD can be traced back to Dr. Rene Laënnec, who was the first to precisely establish a relationship between chronic bronchitis and emphysema [1]. Over the years, advancements in the understanding of the disease, its explicit etiology, detailed pathology and distinct pharmacotherapy have aided in improving patient outcomes [1, 2]. In 1962, the American Thoracic Society Committee defined emphysema as "an anatomic alteration of the lung characterized by an abnormal enlargement of the airspace distal to the terminal, non-respiratory bronchiole accompanied by destruction of the alveolar walls" [3]. Chronic bronchitis on the other hand, was defined in 1965 as "a cough with expectoration that has occurred on most days during at least three consecutive months for more than two successive years" [4]. As of now, the Global Initiative for Chronic Obstructive Lung Disease (GOLD) defines COPD as "common, preventable and treatable disease that is characterized by persistent respiratory symptoms and airflow limitation that is due to airway and/or alveolar abnormalities usually caused by significant exposure to noxious particles or gases" [5].

Analogous to the discovery of COPD which coursed gradually through decades, the establishment of a peculiar treatment therapy for the disease took years to develop. Until the 1950s, no specific treatment was authorized, excepting a few sedatives and antibiotics. Corticosteroids were almost never used. During the 1960s, mechanical ventilators and long-term oxygen therapy measures began to be extensively studied and trialled and were shown to improve outcomes, hence used in patients with longstanding COPD [1]. Smoking as a cause of respiratory derangements was authenticated only in the late 1990s [6]. By the end of the twentieth century, available treatment options included smoking cessation, antibiotics, bronchoactive agents and steroids [7].

Ranked as the fifth leading cause of death in 2002 [8], COPD accounted for six percent of the world's mortality in 2012 [5]. By 2030, it is expected to secure the fourth position and may account for $7.8 \%$ of total deaths globally [8]. The disease is more probable in high-income countries [9]. The development of COPD is multifactorial, risk factors implicated in its etiology include: cigarette smoking, indoor (biomass) or outdoor environmental pollutants, genetic factors and recurrent juvenescent infections of the lower respiratory tract $[5,10]$. Spirometric irregularity, flawed arterial blood gas tests and other findings on physical examination hint to the presence of COPD $[5,10,11]$.

Present day medications used to treat COPD include beta-agonists, parasympatholytics, methylxanthines, corticosteroids, phosphordiesterase inhibitors, and combination therapies incorporating two or more drugs [12]. There has been some controversy regarding the effectiveness of one combination regimen over the other. Therefore, the current research was conducted with the objective of comparing dual drug with triple-drug therapy and evaluating the efficacy of either regimen. Spirometric analysis was utilized for obtaining reliable results.

\section{MATERIALS AND METHODS}

The present prospective observational study was carried out from September 2014 to February 2015 in the Department of Pulmonology, Krishna Institute of Medical Sciences (KIMS) Hospital, Secunderabad, Telengana, India. Data for this study was collected prospectively from case sheets and from consent-obtained questionnaires distributed to patients in both inpatient (IP) and 
outpatient (OP) departments. The study was approved by the KIMS Foundation and Research Centre Ethics Committee (KFRC/EC/ APR/024/2015, dated 14.02.15). All patients diagnosed with chronic obstructive pulmonary disease and aged $40 \mathrm{y}$ or above were the study population. Pregnant or lactating women, patients who portrayed reluctance for enrollment, and those who failed to show up for subsequent review were excluded from the study.

\section{Study procedure}

The study was conducted on 60 patients suffering from COPD. The participants were divided into two groups of 30 each. One group received a dual combination inhaler of formoterol $6 \mu \mathrm{g}$ and budesonide $100 \mu \mathrm{g}$, while the other group was given a triple drug combination inhaler of formoterol $6 \mu \mathrm{g}$, ciclesonide $200 \mu \mathrm{g}$ and tiotropium $9 \mu \mathrm{g}$. Before the commencement of treatment, patients' FEV1 and FVC values were recorded, while 'symptoms encountered' were assessed with the aid of a questionnaire validated by a registered clinician. Patients were required to appear for a follow-up three months succeeding initiation of therapy. During follow-up visits, post-treatment FEV1 and FVC values were charted, while the distribution of questionnaires analogous to those previously distributed, enabled reassessment of any persisting symptoms. Data collected was then subjected to statistical analysis.

\section{Statistical analysis}

We used Microsoft Excel 2007 and mean of samples to compute the observed values of pre-and post-treatment.

The following parameters were analysed statistically:

- FEV1 and FVC values pre-and post-treatment in dual therapy.

- FEV1 and FVC values pre-and post-treatment in triple therapy.

A comparative pre-and post-treatment analysis in either group was then done to assess any improvement in symptoms.

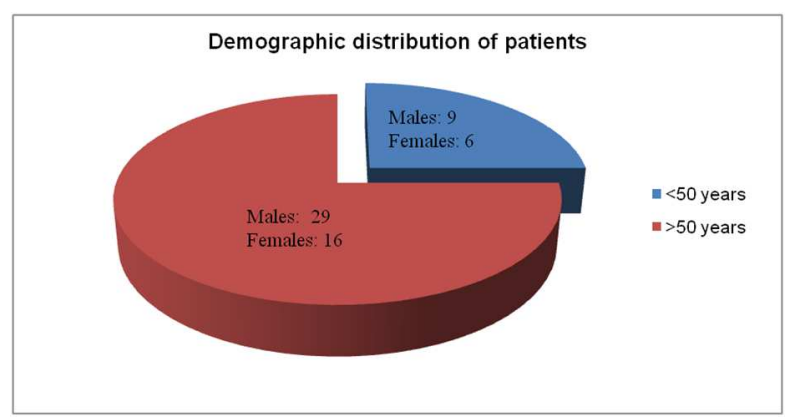

Fig. 1: Demographic distribution of COPD patients

\section{RESULTS}

\section{Demographic distribution of patients}

In the present study, a total of sixty patients were enrolled and distributed according to their age $(<50 \mathrm{y}$ or $>50 \mathrm{y})$ and sex. Fifteen patients were aged below 50 y ( 9 males and 6 females), while the remaining 45 were above 50 y of age ( 29 males and 16 females). Demographic distribution of patients is shown in fig. 1.

\section{Age distribution of patients}

Age distribution of patients was enumerated and it was found that $35 \%$ of the diseased population was aged between 61 and $70 \mathrm{y}$. This was followed by the age group of 51-60 y who constituted another $25 \%$ of the total. Age groups of 41-50 and 71-80 y olds constituted $15 \%$ each. The least prone was the age range of $81-90$ y $(10 \%)$.

\section{Gender wise distribution of patients}

The sample consisted of 38 men (majority of the sample size) and 22 women suffering from the chronic illness. The percentages in men and women were reported as $63.33 \%$ and $36.67 \%$ respectively.

\section{Smokers and non-smokers having COPD}

From the 60 patients enrolled in the study, 38 were males and 22 were females. No female smokers were documented in this prospective study. However, among the 38 men, there were 23 smokers and 15 non-smokers. Smokers accounted for about 38.33\% while non-smokers, from the total, made up the remaining $61.67 \%$.

\section{Presence of symptoms in COPD patients}

We categorised the manifestations of COPD as cough, shortness of breath, fever and haemoptysis. From a sum of 60 patients, 56 experienced cough, accounting for 93.33\%, 51 suffered with shortness of breath, accounting for $85 \%, 27$ presented with pyrexia, constituting $45 \%$, and 9 patients experienced haemoptysis, accounting for $15 \%$ of the total subjects.

\section{Comorbidities in COPD}

Comorbidities such as hypertension, heart diseases, diabetes and others such as psychological disorders are usual among patients with the chronic respiratory disease. Data obtained from the present study demonstrated that majority of patients were hypertensive (70\%); the second most common comorbidity was diabetes mellitus (60\%). Cardiovascular and psychological disorders accounted for 40 and $10 \%$ of the sample size respectively.

\section{Statistical analysis of FEV1 and FVC values}

Statistical analysis was carried out for comparing FEV1 and FVC values pre-and post-treatment in dual and triple therapies, shown in table $1(\mathrm{a})$ and (b).

Table 1: Statistical analysis of FVC and FEV1 values in (a) dual therapy and (b) triple therapy

(a)

\begin{tabular}{|c|c|c|c|c|}
\hline \multirow[t]{3}{*}{ Statistical value } & \multicolumn{4}{|l|}{ Dual therapy } \\
\hline & \multicolumn{2}{|l|}{ FVC } & \multicolumn{2}{|l|}{ FEV1 } \\
\hline & Pre-treatment & Post-treatment & Pre-treatment & Post-treatment \\
\hline Mean & 46.70 & 55.30 & 46.97 & 55.83 \\
\hline \multicolumn{5}{|c|}{ (b) } \\
\hline Statistical value & $\begin{array}{l}\text { Triple therapy } \\
\text { FVC }\end{array}$ & & FEV1 & \\
\hline & Pre-treatment & Post-treatment & Pre-treatment & Post-treatment \\
\hline Mean & 46.50 & 61.40 & 47.10 & 61.37 \\
\hline
\end{tabular}

On thoroughly inspecting the data, the difference between the mean of FVC pre-and post-treatment in dual therapy was found to be 8.60 and the difference between the mean of FEV1 pre-and post-treatment was calculated as 8.87. In triple therapy, the difference between the mean of FVC preand post-treatment was 14.90 and the difference between the mean of FEV1 pre-and post-treatment was 14.27. 


\section{Distribution of patients based on disease severity}

For judging the comparative superiority of one drug regimen over the other, we graded the disease severity based on specific score ranges. Scores of 0-10, 11-20 and 21-30 represented mild, moderate or severe disease states respectively. We then compared the score ranges pre-and post-treatments in either therapy to make a conclusion regarding the efficacy of one over the other.

Comparative distribution of patient's pre-and post-treatment with dual therapy

The former group of subjects undergoing dual therapy were categorized as mild, moderate and severe, with respect to their scores before medication administration. Out of 30 patients, it was observed that $36.67 \%$ patients suffered from moderate COPD, while a majority $63.34 \%$ suffered from severe COPD. No mild cases were documented.

Three months post-treatment, the highest cases observed were those of moderate COPD (66.67\%), followed by mild $(20 \%)$ and severe $(13.34 \%)$ disease. Table 2 compares the scores of patients before and after treatment with dual therapy.

Clearly, the number of patients with severe illness after therapy was found to decrease i.e. 19 cases pre-treatment to 4 cases posttreatment. There was also a marked decrease in the scores calculated from the questionnaire.

Comparative distribution of patient's pre-and post-treatment with triple therapy

The latter group of subjects undergoing triple therapy were classed as mild, moderate and severe, based on their scores before the onset of therapy. From a total of 30 patients, severe cases took the lead $(66.67 \%)$, the successors being moderate $(30 \%)$ and mild cases (3.34\%).

After three months, it was found that $46.67 \%$ were moderate, 43.34\% were mild and the least documented were severe cases $(10 \%)$. Table 3 compares the scores of patients before and after treatment with triple therapy.

Table 2: Distribution of patients according to their scores before and after treatment with dual therapy

\begin{tabular}{lllll}
\hline Score range & Scale & Number of patients & \\
\cline { 2 - 5 } & & Pre- & Post- & Difference \\
\hline $0-10$ & Mild & 0 & $6(20 \%)$ & $6(20 \%)$ \\
$11-20$ & Moderate & $11(36.6 \%)$ & $20(66.6 \%)$ & $9(30 \%)$ \\
$21-30$ & Severe & $19(63.3 \%)$ & $4(13.3 \%)$ & $15(50 \%)$ \\
\hline
\end{tabular}

Table 3: Distribution of patients according to their scores before and after treatment with triple therapy

\begin{tabular}{lllll}
\hline Score range & Scale & Number of patients & \\
\cline { 2 - 5 } & & Pre- & Post- & Difference \\
\hline $0-10$ & Mild & $1(3.34 \%)$ & $13(43.3 \%)$ & $12(40 \%)$ \\
$11-20$ & Moderate & $9(30 \%)$ & $14(46.6 \%)$ & $5(16.67 \%)$ \\
$21-30$ & Severe & $20(66.6 \%)$ & $3(10 \%)$ & $17(56.67 \%)$ \\
\hline
\end{tabular}

Follow-up after treatment demonstrated a decrease in the percentage of patients suffering from severe disease. The documented difference between the percentages of severe cases pre-and post-treatment was more than $50 \%$. This was coupled with a decrease in the scores calculated from the questionnaire.

Table 4: Comparison of scores in dual and triple therapies

\begin{tabular}{|c|c|c|c|c|c|c|c|}
\hline \multirow[t]{3}{*}{ Score range } & & \multicolumn{3}{|c|}{ Dual therapy } & \multicolumn{3}{|c|}{ Triple therapy } \\
\hline & \multirow[t]{2}{*}{ Scale } & \multicolumn{3}{|c|}{ Number of patients } & \multicolumn{3}{|c|}{ Number of patients } \\
\hline & & Pre- & Post- & Difference & Pre- & Post- & Difference \\
\hline $0-10$ & Mild & 0 & $6(20 \%)$ & $6(20 \%)$ & $1(3.34 \%)$ & $13(43.3 \%)$ & $12(40 \%)$ \\
\hline $11-20$ & Moderate & $11(36.6 \%)$ & $20(66.6 \%)$ & $9(30 \%)$ & $9(30 \%)$ & $14(46.6 \%)$ & $5(16.67 \%)$ \\
\hline $21-30$ & Severe & $19(63.3 \%)$ & $4(13.3 \%)$ & $15(50 \%)$ & $20(66.6 \%)$ & $3(10 \%)$ & $17(56.67 \%)$ \\
\hline
\end{tabular}

\section{Comparison of scores in dual and triple therapies}

Comparative analysis between the percentages of pre-and posttreatment in dual and triple therapies portrayed the following conclusions:

- The difference between the percentages of mild cases pre-and post-treatment in dual therapy was found to be $20 \%$; this was contrasted with double the increase in triple therapy (40\%).

- The difference between the percentages of moderate cases preand post-treatment in dual therapy was calculated as 30\%, in contrast to the difference of $16.67 \%$ in triple therapy.

- The difference between the percentages of severe cases pre-and post-treatment in dual therapy was calculated as $50 \%$; this was contrasted with an increase of $56.67 \%$ in triple therapy.

This indicates that post-treatment, dual therapy administration added 6 patients to the mild category, 9 patients to the moderate category and eliminated 15 from the severe grade. On the contrary, triple regimen added 12 patients to the mild category, 5 patients to the moderate category, while eliminating 17 from the severe grade. The data is presented in table 4 .

\section{DISCUSSION}

In 2010, an estimated 384 million people suffered from COPD globally [9]. In India, about 5 lakh deaths are attributable to the disease per year; this means that every minute, one person dies [13]. Progressing from dual to triple-drug regimens, the latter have proven effective over other drug combinations only recently [14].

Our comparative analysis demonstrates a greater increase in the differences of means of both FVC (pre-and post-treatment difference of 8.60 with dual therapy in contrast to 14.90 with triple regimen) and FEV1 (pre-and post-treatment difference of 8.87 with dual therapy in contrast to 14.27 with triple therapy) values in patients receiving triple-drug combination. It can, therefore, be inferred that patients undergoing triple-drug therapy benefitted more than those undergoing dual drug combination therapy.

Our study demonstrates the highest prevalence of the disease in the age group of 61-70 $\mathrm{y}$, followed by the range of 51-60 $\mathrm{y}$ olds i.e. patients 
aged between 51 and 70 y constituted the majority $(60 \%)$ of the population. This was probably due to long-term occupational exposure and indoor and outdoor pollution [5]. Other studies report a higher prevalence in patients aged $70 \mathrm{y}$ and above [15-18], attributing the cause to tobacco smoking and advancing age [15]. The least prone was the age group of 81-90 y, credited to the healthy survivor effect [15, 18], in which individuals succumb to death before $80 \mathrm{y}$ of age owing to chronicity of the illness and associated comorbidities.

Gender wise analysis reports a higher preponderance in males $(63.3 \%)$ compared to females $(36.67 \%)$. This was consistent with the results of other researchers $[9,15-18]$. A contributing element in this regard is habitual smoking in men.

The current research consisted of 23 male smokers, accounting for $60.52 \%$ of the male population and $38.3 \%$ of the total. No female smokers were documented. The two most essential etiologic agents implicated in COPD are smoking and environmental pollutants [19, 20]. As men exhibit considerable exposure to either of these, their dominance in this respect is clearly comprehensible.

The GOLD guidelines, however, have stated increasing age and female sex as risk factors for COPD [5]. Over the past few decades, cigarette smoking by women in developed countries has become 'trendy' [9], leading to more rapidly deteriorating lung function and a greater annual decline in FEV1 [21]. This has contributed to a notable increase in the incidence of the disease among young females aged 50-59 y and above, while prevalence is still dominated by males $[9,15-18,21]$. Additionally, recent researches have evinced a possible link between COPD and autoimmunity. Consequently, as women are more prone to autoimmune disorders, they would unambiguously be inclined to develop COPD [21].

Symptom evaluation revealed that almost all the patients experienced cough (93.3\%) and dyspnoea (85\%). The successors were fever (45\%) and haemoptysis (15\%). While the former two are the result of airway obstruction and excessive mucus secretion [22], latter manifestations may indicate oncoming respiratory infections. However, diagnosis of COPD cannot rely solely on clinical manifestations, as a small percentage of patients present with no respiratory symptoms at all [15]. The guidelines, therefore, portray an organized approach to assessing affected patients [5].

Association between COPD and comorbidities is complex. Our study showed that hypertensive patients constituted $70 \%$ of the sample total. Diabetes mellitus was the second most prevalent comorbidity. This was proceeded by cardiovascular diseases (40\%), pneumonia (25\%) and psychological abnormalities (10\%). The co-existence of a disease alongside COPD is multifactorial and is ultimately specific to the patient [16]. However, several mechanisms have been proposed to explain the relation between the two. Impairment of lung function due to the chronic illness builds pressure in pulmonary vessels, causing pulmonary hypertension. This further increases the workload on the heart and may result in the development of cardiovascular disorders such as ischemic heart disease, heart failure and arrhythmias [23]. Right ventricular failure, if present, may remain unaltered despite ongoing treatment [24]. The relation between diabetes and COPD is intricate, with each pre-existing condition worsening the prognosis of the other. Pre-existing diabetes aggravates COPD through direct harmful effects of hyperglycaemia on lung function, while pre-existing COPD augments diabetes via its deteriorating effects on insulin resistance [25].

After gauging FEV1 and FVC values before and after treatments, we allotted score ranges of 0-10, 11-20 and 21-30 to mild, moderate and severe categories and assessed the superiority of one regimen over the other. From our observations, we concluded that the number of patients suffering from severe COPD decreased significantly in triple-drug therapy trial, indicative of its increased efficacy over dual-drug regimen. Our findings coincided with those of others [26-28].

The current research involved administration of triple therapy to patients independent of disease severity, in contrast to GOLD guidelines which recommend reservation of the triple drug regimen for severe cases with frequent exacerbations [14].
Singh et al. [26] and Cazzola et al. [27] conducted analogous researches by comparing triple therapy involving LABA, LAMA and ICS with LABA+ICS or LAMA alone. Both the authors reported better outcomes with a triple-drug regimen, evident from improvement in pulmonary tests. Singh et al. [26] Additionally inferred that triple therapy is ineffective with a single dose and that it elicits its therapeutic response gradually over a period of two weeks [26]. Anticholinergics exert their effects by blocking parasympathetically induced bronchoconstriction [12]. They also aid in enhancing FEV1, decrease inflation of lungs [26] while minimizing exacerbations [29]. While studies claim the efficacy of tiotropium, salmaterol and fluticasone to be equal to glycopyrronium, salmaterol and fluticasone, there exists minor superiority of the latter in improving FEV1 [30] and eliciting peak response with only a single dose [31].

The use of corticosteroids over longer durations is raising concerns owing to its resistance and related adverse effects [29]. Researches in this field are ongoing, with trials to replace ICS with the better phosphodiesterase- 4 inhibitors or other alternatives, where possible $[12,14]$.

Limitation of the present study was its small sample size. The study was also confined to three months duration and therefore, could not address maintenance therapy and associated adverse effects. The study also excluded the exacerbations of COPD.

\section{CONCLUSION}

In conclusion, our data suggested that the triple drug combination of formoterol, ciclesonide and tiotropium showed more efficacy in patients suffering from COPD than the dual drug combination of formoterol and budesonide. The former group was shown to elicit its therapeutic response by producing a greater reduction in FVC and FEV1 post-treatment. The use of triple therapy also extends in reducing the number of patients suffering from severe COPD. It demonstrates benefits on lung function and improvement of symptoms, thereby enhancing patients' quality of life. Additionally, patients with advanced COPD reported that triple therapy combined with pulmonary rehabilitation provided substantial benefit in terms of lung function.

With the present available literature, the question "Is three better than two?" seems to be answered with conclusive evidence. The new question that arises is "Which three is better?" The search for the most effective triple therapy portraying maximal benefits and with least documented adverse effects is still ongoing.

\section{ACKNOWLEDGEMENT}

The authors are thankful to the staff members of Krishna Institute of Medical Sciences (KIMS) Hospital, Secunderabad, Telengana, India for providing assistance, help and support in the research work.

\section{AUTHORS CONTRIBUTIONS}

All authors have contributed equally to the research work.

\section{CONFLICT OF INTERESTS}

All authors have none to declare

\section{REFERENCES}

1. Petty TL. COPD in perspective. Chest 2002;121:116S-20S.

2. Fishman AP. One hundred years of chronic obstructive pulmonary disease. Am J Respir Crit Care Med 2005;171:941-8.

3. Harris HW. Chronic bronchitis, emphysema and asthma. Am J Public Health Nations Health 1963;53(Suppl 3):7-15.

4. Definition and classification of chronic bronchitis for clinical and epidemiological purposes. A report to the medical research council by their committee on the aetiology of chronic bronchitis. Lancet 1965;1:775-9.

5. Global Initiative for chronic obstructive lung disease: pocket guide to COPD diagnosis, management and prevention; 2017.

6. Pride NB. Smoking cessation: effects on symptoms, spirometry and future trends in COPD. Thorax 2001;56(Suppl 2):ii7-ii10.

7. Burki NK. Chronic airway obstruction. J Fam Pract 1980;11:301-5. 
8. Mathers CD, Loncar D. Projections of global mortality and burden of disease from 2002 to 2030. PLoS Med 2006;3:e442.

9. Adeloye D, Chua S, Lee C, Basquill C, Papana A, Theodoratou E, et al. Global and regional estimates of COPD prevalence: Systematic review and meta-analysis.J Glob Health 2015; 5:020415.

10. World Health Organization. Causes of COPD. Available from: http://www.who. int/respiratory/copd/causes/en/ [Last accessed on 30 Nov 2017]

11. Oliver P, Buno A, Alvarez-Sala R. Arterial blood gas analyses in chronic obstructive pulmonary disease: in the clinical laboratory or as point-of-care testing? Austin J Pulm Respir Med 2015;2:1024.

12. Wells BG, Dipiro JT, Schwinghammer TL, Dipro CV. Pharmacotherapy handbook. $9^{\text {th }}$ ed. McGraw-Hill Education; 2015.

13. Salvi S, Agrawal A. India needs a national COPD prevention and control programme. J Assoc Physicians India 2012;60 Suppl:5-7.

14. Cazzola M, Matera MG. Triple combinations in chronic obstructive pulmonary disease-Is three better than two? Expert Opin Pharmacother 2014;15:2475-8.

15. Afonso ASM, Verhamme KMC, Sturkenboom MCJM, Brusselle GGO. COPD in the general population: prevalence, incidence and survival. Respir Med 2011;105:1872-84.

16. Baty $F$, Putora PM, Isenring $B$, Blum $T$, Brutsche $M$. Comorbidities and burden of COPD: a population based casecontrol study. PLoS One 2013;8:e63285.

17. Anecchino C, Rossi E, Fanizza C, Rosa MD, Tognoni G, Romero M. Prevalence of chronic obstructive pulmonary disease and pattern of comorbidities in a general population. Int J Chron Obstruct Pulmon Dis 2007;2:567-74.

18. Van Durme YMTA, Verhamme KMC, Stijnen T, Van Rooij FJA, Van Pottelberge GR, Hofman A, et al. Prevalence, incidence, and lifetime risk for the development of COPD in the elderly: the rotterdam study. Chest 2009;135:368-77.

19. Mohan H. Textbook of pathology. $6^{\text {th }}$ ed. Jaypee Brothers Medical Publishers (P) Ltd; 2010.

20. Varughese JD, Jayakumari S. A prospective observational study on health-related quality of life in chronic obstructive pulmonary disease patients based on severity. Asian J Pharm Clin Res 2017;10:244-7.
21. Camp PG, O’Donnell DE, Postma DS. Chronic obstructive pulmonary disease in men and women: myths and reality. Proc Am Thorac Soc 2009:6:535-8.

22. Smith J, Woodcock A. Cough and its importance in COPD. Int J Chron Obstruct Pulmon Dis 2006;1:305-14.

23. Imaizumi $Y$, Eguchi K, Kario K. Lung disease and hypertension. Pulse (Basel) 2014;2:103-12.

24. Samanth J, Padmakur R, Mohapatra A, Krishnananda N, Patil N, Karthik RN. Use of tissue doppler imaging to detect right ventricular myocardial dysfunction in patients with chronic obstructive pulmonary disease. Asian J Pharm Clin Res 2017;10:118-24.

25. Glaser S, Krüger S, Merkel M, Bramlage P, Herth FJ. Chronic obstructive pulmonary disease and diabetes mellitus: a systematic review of the literature. Respiration 2015;89:253-64.

26. Singh D, Brooks J, Hagan G, Cahn A, O'Connor BJ. Superiority of "triple" therapy with salmeterol/fluticasone propionate and tiotropium bromide versus individual components in moderate to severe COPD. Thorax 2008;63:592-8.

27. Cazzola M, Andò F, Santus P, Ruggeri P, Di Marco F, Sanduzzi A, et al. A pilot study to assess the effects of combining fluticasone propionate/salmeterol and tiotropium on the airflow obstruction of patients with severe-to-very severe COPD. Pulm Pharmacol Ther 2007;20:556-61.

28. Singh D, Papi A, Corradi M, Pavlišová I, Montagna I, Francisco C, et al. Single inhaler triple therapy versus inhaled corticosteroid plus long-acting $\beta_{2}$-agonist therapy for chronic obstructive pulmonary disease (TRILOGY): a double-blind, parallel group, randomised controlled trial. Lancet 2016;388:963-73.

29. Barnes PJ. Triple inhalers for obstructive airways disease: will they be useful? Expert Rev Respir Med 2011;5:297-300.

30. Aaron SD, Vandemheen KL, Fergusson D, Maltais F, Bourbeau J, Goldstein R, et al. Tiotropium in combination with placebo, salmeterol, or fluticasone-salmeterol for treatment of chronic obstructive pulmonary disease: a randomized trial. Ann Intern Med 2007;146:545-55.

31. Chapman KR, Beeh KM, Beier J, Bateman ED, D'Urzo A, Nutbrown $\mathrm{R}$, et al. A blinded evaluation of the efficacy and safety of glycopyrronium, a once-daily long-acting muscarinic antagonist, versus tiotropium, in patients with COPD: the GLOW 5 study. BMC Pulm Med 2014;14:4. 